\title{
Climate Change, Weather Conditions, and Population Health
}

There is near unanimous consensus that the global climate is warming and most of the warming is attributable to human activities. The world economic expansion has largely been driven by fossil fuels, leading to increasing emissions of greenhouse gases (GHGs). The world's average temperature has risen at a rate of $0.07{ }^{\circ} \mathrm{C}$ per decade since 1880 and nearly triple that rate since the 1990s. In addition to heat waves and cold spell, climate change may lead to a wide range of extreme weather conditions, including drought, floods, typhoons, windstorms, and landslides. Exposure to non-optimal temperatures and extreme weather conditions has been associated with a range of adverse health outcomes, including excess mortality and morbidity from various causes, and changes in the ecology of infectious diseases. For example, in China, 14.3\% of non-accidental mortality during 2013-2015 may be related to non-optimal temperatures, with $11.6 \%$ and $2.7 \%$ explainable by exposure to cold and heat, respectively (1). The recent global burden of diseases study (GBD 2019) shows that non-optimal temperatures are among the ten leading causes of death worldwide (2). A projection study showed that under high-emission scenarios, the negative health impacts of climate change would disproportionately affect warmer and poorer regions of the world (3). Climate change can also affect climate-sensitive infectious diseases carried by animal hosts or vectors, including malaria, dengue fever, schistosomiasis, Japanese encephalitis, and Angiostrongylus cantonensis.

In this special issue, we invited colleagues from Sun Yat-Sen University, China CDC, Peking University, and Shanghai Meteorology Bureau to report their latest findings on climate change, weather conditions, and population health. Qi and coworkers examined the associations between ambient temperature and years of life lost from stroke in 93 Chinese cities (4). Zhang et al. assessed the regional distribution of health vulnerability to extreme heat in China (5). Using a modelling approach, Huang et al. estimated the $\mathrm{PM}_{2.5}$-related health impacts from climate change and air pollution emission control in China (6). Finally, Ye et al. evaluated the impact of a health forecasting service on outpatient visits for chronic obstructive pulmonary disease patients in Shanghai ( 7 ).

In short, the findings from this special issue further confirmed that climate change and extreme weather conditions have posed substantial health risks for population health in China as well as other parts of the world. Future research will need to improve characterization of climate-health relationships, to develop effective and adaptive strategies to help reduce the health risks of climate change, and to promote healthy lifestyles in line with the reduction of greenhouse gas emissions. Finally, GHG emissions need to be controlled. China aims to reach carbon emissions peak before 2030 and achieve carbon neutrality before 2060. Consideration of the health impact of climate change and extreme weather conditions can help decision-makers with appropriate urgency.

doi: $10.46234 / \mathrm{ccdcw} 2021.124$

${ }^{1}$ School of Public Health, IRDR ICoE on Risk Interconnectivity and Governance on Weather/Climate Extremes Impact and Public Health, Fudan University, Shanghai, China.

Submitted: May 16, 2021; Accepted: June 01, 2021

\section{REFERENCES}

1. Chen RJ, Yin P, Wang LJ, Liu C, Niu Y, Wang WD, et al. Association between ambient temperature and mortality risk and burden: time series study in 272 main Chinese cities. BMJ 2018;363:k4306. http://dx.doi.org/10.1136/bmj.k4306.

2. GBD 2019 Risk Factors Collaborators. Global burden of 87 risk factors in 204 countries and territories, 1990-2019: a systematic analysis for the Global Burden of Disease Study 2019. Lancet 2020;396(10258):1223 - 49. http://dx.doi.org/10.1016/S0140-6736(20)30752-2.

3. Gasparrini A, Guo YM, Sera F, Vicedo-Cabrera AM, Huber V, Tong SL, et al. Projections of temperature-related excess mortality under climate change scenarios. Lancet Planet Health 2017;1(9):e360 - 7. http://dx.doi.org/10.1016/S2542-5196(17)30156-0.

4. Qi JL, Tian F, Ai SQ, Yin P, Zhou MG, Wang LJ, et al. Association between ambient temperature and years of life lost from stroke - 30 PLADs, 2013-2016. China CDC Wkly 2021;3(23):485 - 9. http://dx.doi.org/10.46234/ccdcw2021.125.

5. Zhang XH, Li YH, Cheng YB, Wang Y, Wang Y, Yao XY. Assessment of regional health vulnerability to extreme heat — China, 2019. China CDC Wkly 2021;3(23):490 - 4. http://dx.doi.org/10.46234/ccdcw2021.126.

6. Huang J, Tian H, Wang JW, Yang T, Peng YR, Wu SW, et al. A modeling study on $\mathrm{PM}_{2.5}$-related health impacts from climate change and air pollution 
emission control - China, 2010s and 2040s. China CDC Wkly 2021;3(23):500 - 6. http://dx.doi.org/10.46234/ccdcw2021.128.

7. Ye XF, Li ZT, Zhou X, Ruan XN, Lin T, Zhou J, et al. The impact of a health forecasting service on the visits and costs in outpatient and emergency departments for COPD Patients — Shanghai Municipality, China, October 2019-April 2020. China CDC Wkly 2021;3(23):495 - 9. http://dx.doi.org/ $10.46234 / \mathrm{ccd}$ cw2021.127.

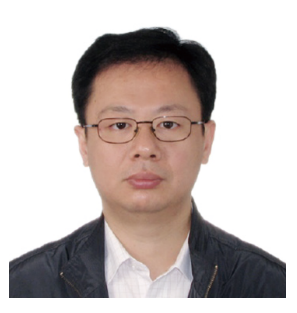

Haidong Kan, Ph.D.

Associate Dean, School of Public Health, Fudan University, China

Cheung Kong Scholar Chair Professor, Ministry of Education, China

Associate Editor of International Journal of Epidemiology

Associate Editor of Environmental Health Perspectives 